\title{
The problem of professional identity in the professional development of the individual
}

\author{
Lyudmila Zheldochenko ${ }^{1}$ and Oksana Nikolenko ${ }^{2, *}$ \\ ${ }^{1}$ Southern Federal University, 344006, Big Sadovaya street 105/42, Russia \\ ${ }^{2}$ Don State Technical University, 344003, Gagarin sq., 1, Rostov on Don, Russia
}

\begin{abstract}
The article analyzes the problem of professional development of the individual from the moment of choosing a profession at the senior stage of training in an educational institution and building an individual professional route, to the formation of professional identity at the stage of completion of training at a University and readiness to engage in independent professional activity. The article deals with the issues that lie at the origins of the professionalization of the individual, related to the formation of complete, clear ideas at the stage of training at school. The results of an empirical study of the professional identity of University graduates are presented. The respondents were students-bachelors in the number of 150 people. The following methods were used: "A questionnaire aimed at studying ideas about the object of activity (E. I. Rogova), methods for studying the status of professional identity (A. A. Azbel, A. G. Gretsov); diagnostics of self-efficacy using the Maddux and Scheer method. It is established that the status of formed professional identity prevails among graduate students with high self-efficacy, the status of moratorium prevails among graduate students with medium self-efficacy, and the status of imposed professional identity distinguishes graduate students with low self-efficacy.
\end{abstract}

\section{Introduction}

The relevance of the studied problem is due to the fact that the basis of successful professionalization of the individual is a formed professional identity based on adequate representations of their professional future, clear ideas about their professional activities and conscious self-identification with the image of a professional. The problem of professional identity is urgent in the perspective of training future professionals at the stage of training at the University and their formation in independent professional activity. It is obvious that adolescence is a sensitive period for self-determination, both in the personal sphere and in the professional sphere. At the same time, it is important to note that the process of identity formation continues throughout life, being a factor of psychological well-being, life satisfaction and personal growth of each person in the modern, rapidly changing world. Therefore, the most relevant is the study of the formation of professional identity in youth, when leading, teaching and professional activities develop cognitive and

\footnotetext{
${ }^{*}$ Corresponding author: Nikolenko.of@mail.ru
} 
professional interests, forming professional and life plans, the problem of choice of profession, as well as during early adulthood, the period of positioning themselves in the adult world, on the stage of professional education and beginning of professional activities [1]. Research is devoted to the phenomenon of professional identity, both in foreign psychology and in domestic science. So, H. Tajfel and John. Turner identity refers to a cognitive system that performs the role of regulating behavior in a variety of settings. According to K's theory. Rogers 'identity is an organized, coherent conceptual Gestalt constructed from perceptions of the characteristics of" I " or "me" in various life contexts, as well as the values associated with these perceptions [2]. Erickson identified three levels of identity: ego identity - the most fundamental level-stable over time representations of oneself, including various intrapsychic conflicts; personal identity-a set of goals, values, and beliefs acquired by a person; social identity, a more contextual level, implying identification with the ideals, values, and beliefs of the group [3]. Marcia, studying the phenomenon of identity, identifies four possible identity statuses in such life contexts as profession and ideology, of which the achieved and predetermined ones indicate the presence of a" stable "personal identity, and the moratorium and diffuse status indicate an" unstable " identity [4].

In Russian psychological science, the phenomenon of identification was initially studied from the position of self-awareness, and later evolved into an independent construct, similar in content to the professional Self-concept, professional attitude. Thus, according to A. A. Azbel, professional identity is identification with a certain professional group of people, acceptance of its goals and values, and awareness of oneself as a member of this group. We agree with the author that it is in high school age, at the stage of primary choice of professional roles, professional route, at the stage of primary knowledge of the professional field of knowledge begin to lay the prerequisites for the formation of a complete professional identity through the formation of professional intentions and adequate professional ideas. Azbel has developed a theoretical status model for the formation of professional identity, which is based on two parameters for determining the status of the phenomenon under study: 1) the presence or absence of a crisis of professional choice (a search of variousalternatives to professional development); 2) the presence of independent and conscious acceptance of educational and professional plans, goals and beliefs [5]. L. B. Schneider identifies the mechanism of awareness as a Central component of identification, defining it as a psychological category related to the awareness of one's belonging to a certain profession and a certain professional community [6]. Fedotova empirically found that depending on the stages of formation of professional identity, under the influence of various pedagogical conditions, the ratio of components of professional identity changes. The importance of ideas about yourself as a future specialist, about your ability to implement educational and professional goals, the presence of formed judgments about yourself, your own life, expressed attitude to the meanings of the past, present and future, satisfaction with life and its meaningfulness increases. According to S. V. The Conditions that ensure the optimal level of professional self-determination of high school students are: personal maturity, adequacy of self-assessment of abilities for mastering the future profession, the degree of completeness of ideas about the content of future professional activity, the effectiveness of psychological and pedagogical support for the formation of their professional self-determination [7, 8, 9]. Most researchers associate adolescence with the choice of profession, calling it a period of realistic option. However, practice shows that the primary choice of profession made by a person at this age often occurs unconsciously, under the influence of the opinion of parents or significant adults, and therefore turns out to be unsuccessful. Professional plans at the stage of completion of school often have the character of dreams, they are focused on emotionally attractive professional roles, optants do not evaluate their potential and abilities, the specifics of the chosen professional activity 
and the requirements of the profession to the individual. V. D. Bragina, E. I. Rogov, M. V. Naumenko, V. N. Obnosov, I. A. Pankratova and others are devoted to the problem of formation of professional ideas. The authors empirically found that the formed professional ideas contribute to high educational and professional motivation, self-efficacy, and the formation of a full professional identity. Ideas about professional activity and about yourself as a professional are formed from course to course and are refined and detailed when implementing practices in the educational process $[10,11]$. According To E. P. Yermolaeva, professional identity is interpreted as a system characteristic of the subjectsocial-activity correspondence, as a characteristic of the acceptance of professional values, as a harmonious identification with the activity or instrumental identity, society or external identity and oneself or internal identity.

G. M. Andreeva, T. M. Buyakas, M. V. Zakorotnaya, L. M. Putilova, L. B. Schneider and others were engaged in determining the conditions and studying the determinants of professional identity formation in various life contexts. According to L. B. Schneider, the sources of professional identity formation can be called the following factors: objectively existing educational and professional component; subjectively expressed system of expectations and preferences, ideal images of the profession; recognition by others of you as a professional; professional self-presentation; professional norms and attributes; emotional-positive background on which primary information about their profession was obtained; positive perception of themselves as a subject of professional activity; emotionalpositive acceptance of their belonging to the professional community; successful development of the rules and norms of professional activity; a measure of responsibility that an individual can take on; the level of personal development; motivational readiness for self-realization in their chosen professional field [12]. According to empirical research, D. A. The formation of personal and professional identity in youth and early adulthood occurs heterochronously, the formation of personal identity occurs at a faster pace, and is a prerequisite for achieving professional identity. In the research of E. I. Rogov, M. V. Naumenko and others. it is established that there are significant relationships between the formation of the status of professional identity and self-efficacy indicators, as well as significant correlations between the parameters of professional representations and the degree of expression of professional identity statuses. The researchers concluded that the more adequately and holistically formed a person's professional ideas about himself, about the chosen professional activity and the requirements it imposes on the individual, the more pronounced the status of the formed identity, as well as the higher the self-efficacy, the more complete the professional identity $[13,14]$. The formation of identity is expressed in an increase in the number of signs of professional activity and professional relationships reflected in the consciousness of a specialist, in overcoming the stereotypes of the professional image, in a holistic vision of oneself in the context of all professional activities. The main factors influencing the formation of professional identity, L. M. Fedotova considers: a group of organizational and pedagogical factors that can be managed in the organization of the educational process, and includes: solving practice-oriented tasks in the learning process; differentiated tasks taking into account the interests and capabilities of students; acquaintance with representatives of the profession; individual; work in the learning process; use of productive learning technologies.

Self-effectiveness of a person is one of the personal factors that influence success in any activity, including professional ones. Self-effectiveness determines the expected results of a person's activities, which largely depend on their ideas about how well they will cope with a task in a particular situation, including professional ones. The way a person evaluates their own performance determines for them either the expansion or limitation of the choice of activity; the efforts that they will need to make to overcome obstacles and frustrations; the persistence with which he will solve problems. Self-assessment of effectiveness affects 
motivation, forms of behavior and the emergence of emotions. A person who is aware of their effectiveness makes more effort to perform complex tasks compared to those who have doubts about their abilities. A high level of self-efficacy associated with the expectation of success usually leads to a good result and, therefore, promotes self-esteem. People who believe in their ability to solve a problem will be more persistent in achieving their goals and overcoming any obstacles to progress. They will not be prone to selfcriticism. Those who are aware of their high efficiency always imagine a successful scenario that will provide them with positive guidelines for building behavior. In this way, they consciously rehearse successful solutions to potential problems. People with high selfefficacy tend to be more persistent, less anxious, and have greater learning and self-learning abilities. Lowself-effectiveness is associated with expectations of failure, failure, and usually leads to failure, leads to a decrease in self-esteem. Those who consider themselves unable to achieve success pay great attention to their personal shortcomings, often wear themselves out with self-criticism due to their own incompetence or lack of relevant knowledge, skills and abilities. They mentally imagine a bad behavior scenario and focus on the fact that everything will be bad.

Self-efficacy - a person's belief in their ability to achieve a certain result at a certain cost. This belief is based on knowledge and previous experiences. The higher the selfefficacy, the greater the results a person expects from himself at equal costs [15]. In the scientific works of Russian psychologists A. A. Derkach, A.V. Gagarin, A. A. Bodalev, V. G. Zazykin, E. V. Selezneva, R. L. Krichevsky, T. O. Gordeeva, K. M. Gaidar, M. V. Chistov, T. M. Malanin and others, the issue of self-efficacy is given great attention in the field of professional activity. In a number of scientific papers, the authors pay great attention to the theory of self-efficacy, considering a person as a subject of labor and professional development. Self-effectiveness is considered as a socially significant component in terms of society's interest in the effectiveness and professionalism of specialists. Despite a large number of studies of the problem of self-efficacy, the practical question of the mechanisms that affect its development is still poorly understood. Gaidar K. M. she clarified the definition of self-efficacy as follows: self-efficacy is a combination of a person's ideas about their capabilities and abilities to be productive in carrying out their activities, communication, and their confidence that they will be able to realize themselves in them and achieve the expected objective and subjective effect [16]. According to I. V. Self-efficacy is a belief in one's own ability to be successful in solving certain types of problems. Vasilyeva considers self-efficacy as a person's confidence in their own specifically designated competence, in their ability to organize and perform actions necessary for certain achievements in a particular activity [17].

Thus, the phenomenon of professional identity is closely related to such concepts as professional representations and self-efficacy. Professional ideas are the basis for selfidentification of a person in the professional sphere. self-effectiveness allows you to assess your own potential and achieve your goals, as well as successfully solve your professional tasks.

\section{Problem statement}

The phenomenon of professional identity has been studied both in foreign psychology and in Russian science. In Russian psychology, such researchers as M. R. Ginzburg, I. S. Cohn, N. S. Pryazhnikov, E. A. Klimov and others are engaged in the development of professional identity problems. In the works of L. B. Schneider, the definition of the concepts of identity and professional identity is given. It compares professional identity with other concepts used in career guidance, identifies the stages of its development, and examines its features and characteristics. The problem of personal identity was studied in line with the study of 
consciousness (N.In. Antonova, V. V. Stolin, I. I. Chesnokova, etc.) and self-determination (K. A. Abulkhanova-Slavskaya, L. I. Bozhovich, L. S. Vygotsky, S. L. Rubinstein, etc.). The problem of identity is considered in the works of social psychologists $(\mathrm{N}$. In. Antonova, I. V. Romanov, V. A. Yadov, etc.). Among the researchers of the problem of personal and professional identity should also be L. B. Schneider, A. A. Azbel, V. R. Arestova, J. P. Povarenkov, H. H. Gunger, S. A. Drozdov. The problem of professional identity from the point of view of adaptation of a person to a certain profession was addressed by: A. A. Azbel, Yu. P. Povarenkov, L. B. Schneider, and others. Questions of successful implementation of a person-oriented educational process, in which each student can build their own educational trajectory are reflected in the works of T. p. Afanasiev, C. S. Kravtsov, A. G. Kasprzhak, A. A. Kuznetsov, N. V. Nemov, A. A. Pinsky, V. I. Pudenko, L. O. Filatov, S. N. Chistyakov, and others..

High school students face a difficult task of choosing a profession, which is quite difficult to solve independently. It is obvious that they need the help of teachers in designing and forming an individual educational and professional route, in accordance with their aptitudes, skills, Hobbies, as well as the requirements of the profession. Professional self-determination in close relationship with the General process of self-determination and self-realization of the individual is considered in the scientific works of $\mathrm{K}$. A. Abulkhanova-Slavskaya, A.V. Batarshev, V. P. Bondarev, E. M. Borisova, L. S. Vygotsky, M. R. Ginzburg, N. P. Kapustina, A. N. Leontiev, S. L. Rubinstein, V. F. Safina, D. I. Feldstein, and others..

Professional self-determination as a process of assimilation of social roles in the process of socialization was also considered by A. G. Asmolov, T. I. Ekimova, N. E. Kasatkina, E. A. Klimov, I. S. Kon, T. V. Kudryavtsev, N. S. Pryazhnikov, T. V. Rogacheva, E. V. Titov, S. N. Chistyakova, P. A. Shavir, and others. Of interest are the results of research on the problem of professional self-determination and adaptation of students to independent work (S. S. Grinshpun, I. Yu. Kuznetsov, I. V. Kuznetsov, S. P. Kryagzhde, L. M. Mitina, Z. A. Reshetova, A. B. Sukharev, P. P. Shavir, etc.). The research of the identity of the individual is devoted to the work of U. James, I. S. Cohn, A. N. Leontiev, B. C. Merlin; B. C. Mukhina; A. Freud; E. Fromm, etc.

The analysis of empirical psychological and pedagogical research on various aspects of professional self-determination and professionalization of the individual has shown that, despite the breadth of research issues, research on the formation of a complete professional identity in General, and the problem of professional identity of graduate students in connection with self-efficacy, in particular, is not sufficiently presented in science.

\section{Purpose of research}

The purpose of this study was to study the professional identity of students-graduates of the University, as well as to identify the features of professional identity of students-graduates with different self-efficacy.

\section{Method of research}

In our study, the following methods were used to confirm the hypothesis that the professional identity of graduate students with different levels of self-efficacy may differ: "A questionnaire aimed at studying ideas about the object of activity (E. I. Rogova), methods for studying the status of professional identity (A. A. Azbel, A. G. Gretsov); diagnostics of self-efficacy using the Maddux and Scheer method. The selected methods correspond to the tasks of empirical research and provide reliable results. 


\section{Description of the study}

Respondents of the empirical study were students-graduates of the fourth year of the bachelor's degree in psychology and education of the southern Federal University in the number of 150 people. Rostov-on-don. Among them, $12 \%$ of boys, $88 \%$ of girls, age limits from 22 to 25 years. The study was conducted in several stages. At the first stage, a theoretical analysis of the problem of forming a complete professional identity of studentsgraduates of the University was carried out, the phenomenon of professional identity and self-efficacy in the scientific psychological and pedagogical literature was studied. The diagnostic tools were selected. Then, in two stages, an empirical study was conducted. First, the respondents ' self-efficacy was studied using the Maddux and Scheer methodology. The obtained results are statistically processed and analyzed. Further, the ideas about the object of future activity were studied using the questionnaire of E. I. Rogov. aimed at studying the concepts of the object of activity and the status of professional identity when using the methodology of A. A. Azbel, A. G. Gretsov in graduate students with different levels of self-efficacy. The obtained results are processed statistically, the analysis of the obtained results is carried out, and conclusions are made.

\section{Conclusion}

According to the results of the study, the majority of graduate students (45.3\%) showed an average level of self-efficacy, about a third of graduate students showed a low level of selfefficacy, and only a fourth of the subjects showed a high level of self-efficacy. Therefore, it can be assumed that graduates with an average level of self-efficacy have a sufficient level of self-confidence and self-esteem, a positive self-attitude; they perceive themselves as people on whom the results achieved depend; accept themselves as they are, but maybe the flaws cause them concern; most often realize that they themselves are responsible for their own life and professional success, although sometimes do not exclude the role of external factors in operation; quite often show reflexive abilities, able to analyze their feelings, desires, thoughts, actions results, but not prone to soul-searching.

Graduate students with a high level of self-efficacy already understand their professional qualities and can update them. Graduate students with a low level of selfefficacy have a lack of trust in their own behavioral abilities. High self-efficacy is associated with the expectation of success and usually leads to positive results. In contrast, low self-efficacy is associated with the expectation of failure, leads to failure, and thus reduces self-esteem. A person who considers himself unable to cope with difficult situations pays excessive attention to his shortcomings and is constantly engaged in selfflagellation about his own incompetence. Conversely, a self-aware person imagines a successful scenario that provides positive guidelines for organizing their behavior, and consciously loses options for successful actions and decisions.

In addition, self-effectiveness determines the expected results that are formed in the individual. In other words, the expected results of a person's activity largely depend on their ideas about how well they will cope with the task in a particular situation. The more confident a person is in their ability to perform an activity, the higher they set the bar for themselves and thus form an image of the desired results.

Further, the respondents were divided into three groups:Group 1 - graduate students with a high level of self-efficacy; group 2-graduate students with an average level of self-efficacy; group 3 - graduate students with a low level of self-efficacy. Further, professional representations were studied in each group of respondents. check assumptions about the reliability of differences, we carried out statistical processing of the data using the criterion 
Kruskal Wallace. As a result, significant differences were found in the indicators of the evaluation factor $(\mathrm{H}=58.476, \mathrm{p}=0.000)$ and the strength factor $(\mathrm{H}=67.325, \mathrm{p}=0.000)$.

Table 1. Indicators of the significance of differences in the severity of structural components of representations of the object of activity among graduate students with different professional identity statuses

\begin{tabular}{|c|c|c|}
\hline & ratingfactor & powerfactor \\
\hline Chi-square & 58,476 & 67,352 \\
\hline st.sv. & 2 & 2 \\
\hline Asympt. GNP. &, 000 &, 000 \\
\hline
\end{tabular}

Thus, it can be concluded that graduate students with the status of a formed professional identity and graduate students with the status of a moratorium, the object of future activity is presented positively as contributing to the development of strong-willed qualities, confidence, independence, and a tendency to rely on their own strength in difficult situations, giving it socially desirable characteristics, in a certain sense, satisfied with all aspects of future professional activity. Graduate students with the status of an imposed professional identity and an uncertain state of professional identity have partial, incomplete, and unformed ideas about their future work.

Then, professional identity was studied in each group. It is established that the degree of expression of professional identity statuses is different. Thus, the formed professional identity is more inherent in students-graduates with high self-efficacy. Then, according to the degree of severity, there are indicators of students-graduates with average and low selfefficacy. The uncertain state of professional identity is more typical for graduate students with high and medium self-efficacy. A crisis or moratorium is typical for graduate students with average self-efficacy. Imposed professional identity distinguishes graduate students with low self-efficacy. In order to check the identified differences, statistical data processing was performed using the Kruskal-Wallis criterion.

Table 2. Indicators of the significance of differences in the severity of professional identity statuses graduate students with different levels of self-efficacy

\begin{tabular}{|c|c|c|c|}
\hline & $\begin{array}{c}\text { Formed professional } \\
\text { identity }\end{array}$ & $\begin{array}{c}\text { Moratorium } \\
\text { crisisofchoice) }\end{array}$ & $\begin{array}{c}\text { Imposedonprofessi } \\
\text { onalidentity }\end{array}$ \\
\hline Chi-square & 49,453 & 78,248 & 51,543 \\
\hline st.sv. & 2 & 2 & 2 \\
\hline $\begin{array}{c}\text { Asympt. } \\
\text { GNP. }\end{array}$ &, 000 &, 000 &, 000 \\
\hline
\end{tabular}

The results show statistically significant differences in the severity of indicators for the status of formed professional identity $(\mathrm{N}=49.453, \mathrm{p}=0.000)$, Moratorium (crisis of choice) $(\mathrm{N}=78.248, \mathrm{p}=0.000)$, imposed professional identity $(\mathrm{N}=51.543, \mathrm{p}=0.000)$. Thus, statistically proven, the predominant manifestation of status formed a professional identity among graduate students with high self-efficacy, Moratorium (crisis choice) from graduate students with medium self-efficacy and the severity of the imposed status of a professional identity among graduate students with medium self-efficacy. Along with this, the study revealed the following features:

- the status of formed professional identity prevails among graduate students with high selfefficacy. They clearly represent their professional future, have clear ideas about their 
professional activities and consciously identify themselves with the image of a teacher, they are ready for independent professional activity.

- graduate students with average self-efficacy have the status of a Moratorium (crisis of choice). They are characterized by considering alternative options for professional development, they are actively trying to get out of the crisis of choice by making a meaningful decision about their future.

-the status of imposed professional identity prevails among graduate students with low selfefficacy. They are distinguished by the choice of a professional path based on the opinion of parents and significant adults, which at the stage of completion of training leads to great doubts about their professional future and the possibility of professional self-realization in the chosen activity.

Thus, the conducted empirical research allowed us to study in more detail the phenomenon of professional identity and self-efficacy, to identify the features of professional identity in graduate students with different self-efficacy. Prospects for further research are relevant in the direction of studying the problem of psychological and pedagogical support for the process of professional self-determination and the formation of professional identity statuses at the initial stage of the option.

\section{References}

1. L. M. Fedotova, Formation of professional identity of students in the process of studying at the University: Avgoref. dis.... Cand. educational Sciences, 21 (Kemerovo, 2011)

2. K. Rogers, A Humanistic psychology. Theory and practice, ED: MODEK, NOU VPO Moscow psychological and social University, 450 (2013)

3. https://www.livelib.ru/author/322972/top-karl-rensom-rodzhers (Last accessed 12.07.2020)

4. D. Elkind, Eric Erickson and the eight stages of human life, 160 (Moscow, Institute of psychology of the Russian Academy of Sciences, 2013)

5. Sh. Hassan, Employee attachment to workplace: a review of organizational and occupational identification and commitment. International journal of organization theory and behavior, 15(3), 383-422 (2012)

6. L. S. Ilyushin, A. A. Azbel, M. D. Fries, Preparing russian schoolchildren for the artes liberales model of education. Kazan pedagogical journal, 129-136 (2019)

7. L. B. Schneider, Psychology of identity: textbook and practice for universities. 2nd ed., reprint, 328 (Moscow, yurayt publishing house, 2020)

8. S. I. Sotnikova, O. A. Prokudina, Professional orientation in the context of the concept of continuous education. Labour economics, 6(3), 1059-1078 (2019)

9. Ju. Rashupkina, O. Nikolenko, others, Specific features of students ' personal maturity and personal immaturity depending on their social status. In the collection: INTED2017. 11th International Technology, Education and Development Conference Conference proceedings. IATED Academy, 6300-6303 (2017)

10. A. Korochentseva, E. Suroedova, N. Khachaturyan, O. Nikolenko, Pupil's representation about the socio-psychological qualities of teachers in the process of effective meaning transmission SHS Web of Conferences, 70, 08020 (2019) https://doi.org/10.1051/shsconf/20197008020 
11. A. M. Sheveleva, M. V. Naumenko, I. A. Pankratova, E. I. Rogov, L. D. Zeldochenko, Career orientations and motivation of top and middle-level managers. Opción, Año 35, Especial, 21, 1590-1607 (2019) ISSN 1012-1587/ISSNe: 2477-9385

12. E. I. Rogov, L. D. Zeldochenko, Risks of pedagogical profession: the determination of deformations by the sphere of teacher's activity. Advances in Social Science, Education and Humanities Research, 321, 175-179 (2019)

13. L. Zheldochenko, N. K. Epritskaya, Representations about the subject of future activities by students in the classroom profile training, SHS Web of Conferences, 70, 08047 (2019) https://doi.org/10.1051/shsconf/20197008047

14. O. Nikolenko, L. Zheldochenko, N. Lomova, Psychological and pedagogical conditions for the formation of value-semantic sphere of students of technical specialties E3s Web of Conferences, 175, $15029 \quad$ (2020) https://doi.org/10.1051/e3sconf/202017515029

15. L. D. Zheldochenko, E. I. Rogov, The Role of professional representations in shaping the trajectory of professional development / proceedings of the southern Federal University. Pedagogical Sciences. SFU Publishing house, Rostov, 12 (2015)

16. I. A. Umanskaya, V. V. Golubev, self-efficacy and coping behavior of students during their University Studies. Bulletin of Kostroma state University. Series: Pedagogy. Psychology, 118-123 (2020)

17. S. N. Gonchar, Self-Efficacy as a professional quality of future teachers-psychologists. Pedagogical skills: materials of the international conference. scientific conference. (Moscow, Buki-Vedi, 2012)

18. A. V. Chaplin, S. S. Shatskaya, Factors influencing the self-efficacy of the individual. International journal of experimental education, (11-6), 991-993 (2015) http://expeducation.ru/ru/article/view?id=9552 (Last accessed 12.07.2020) 